\title{
DOSSIÊ \\ O Ponto Cantado de Umbanda como fonte para o Ensino de História
}

\author{
The Singing Point of Umbanda \\ as a source for Teaching History
}

\author{
Jaciely Soares da Silva \\ Doutora em História Social pela UFU \\ Professora de Didática e Fundamentos da Educação no IFNMG \\ jacielysoares@gmail.com
}

Admilson Eustáquio Prates

Doutor em Ciências da Religião pela PUC-SP

Professor de Sociologia e Filosofia no IFNMG

admilson.prates@ifnmg.edu.br

\begin{abstract}
RESUMO: O objetivo deste texto é apresentar e discutir a possibilidade do uso de Pontos Cantados como fonte para o Ensino de História na Educação formal no que tange a proposta de debate a partir da promulgação da Lei Federal 10.639/03 que estabelece a obrigatoriedade do ensino de História e Cultura Africana e Afro-brasileira nos currículos escolares. Para tanto, em um primeiro momento discutimos a Lei como resultado de um longo processo de luta na busca pelo reconhecimento africana e afro-brasileira na formação do Brasil, em segundo apresentamos a Umbanda como um fenômeno religioso brasileiro, e e por últimos expomos os Pontos cantados como possibilidade de fonte histórica para o Ensino de História, problematizando seu uso como documento para observação, problematização e análise na construção do conhecimento histórico na educação formal.
\end{abstract}

PALAVRAS-CHAVE: Ensino de História. Ponto cantado. Fonte documental.

ABSTRACT: The purpose of this text is to present and discuss the possibility of using Sung Points as a source for the Teaching of History in formal Education with regard to the debate proposal from the promulgation of Federal Law 10.639 / 03 that establishes the mandatory teaching of African and Afro-Brazilian History and Culture in school curricula. Therefore, in the first moment we discussed the Law as a result of a long process of struggle in the search for African and Afro-Brazilian recognition in the formation of Brazil, in the second we presented Umbanda as a Brazilian religious phenomenon, and lastly we presented the Ponto sung as a possibility of a historical source for the Teaching of History, questioning its use as a document for observation, questioning and analysis in the construction of historical knowledge in formal education.

KEYWORDS: Teaching History. Sung Point. Documentary source. 
Revista do Corpo Discente do Programa de Pós-Graduação em História da UnB Em TEMPO dE HistóRIAS | Brasília-DF | n. 36 | p. 29-46 | jan./jun. 2020.

ISSN 2316-1191

Discutir sobre a História e Cultura Africana e Afro-Brasileira nos currículos escolares requer um trabalho cuidadoso que vai muito além do cumprimento da obrigatoriedade de abordar a temática em sala de aula da Educação Básica brasileira, em conformidade com a Lei 10.639/03, que alterou a Lei de Diretrizes e Bases da Educação (Lei 9394/96). Primeiro, porque a temática se apresenta complexa, ampla e diversificada, no entanto, imprescindível. Segundo, porque as propostas de debates e abordagens conceituais e epistemológicas da temática desde sua gênese expunham a necessidade de romper com preconceitos construídos sobre História e Cultura Africana e Afro-Brasileira ainda presentes no Brasil, tal como debatido por Schwarcz (2001).

A implementação da Lei 10. 639/03 no currículo escolar teve como um dos princípios atender duas demandas urgentes: evidenciar historicamente a contribuição do povo negro nas áreas social, econômica e política, ressaltando sua participação na formação de uma sociedade multicultural e com especificidades construídas por meio de vários sujeitos sociais, abolindo, assim, com a ideia de um passado único, homogêneo e eurocêntrico (COUTINHO, 2008) e instituir instrumento que possa assegurar e promover os direitos de todos, sendo a educação o fator decisivo na luta de combate ao preconceito e à discriminação racial. Ou seja, a implementação da Lei 10 . 639/03 se deu numa proposta de intervir diretamente na realidade social, logo o espaço educacional é campo para tal demanda (BITTENCOURT, 2005).

Para Vera Maria Candau (2008), a educação, como espaço de conhecimento, assume o papel de fomentar nos estudantes o reconhecimento do outro, capaz de favorecer a construção de projetos comuns, pelos quais as diferenças sejam dialeticamente integradas. Estes princípios e seus desdobramentos mostram exigências de mudança de mentalidade, de maneiras de pensar e agir dos indivíduos em particular, assim como das instituições e de suas tradições culturais, de forma que o ensino da diversidade cultural resulta "[...] não apenas em trazer para o centro das discussões educacionais as temáticas afro, como também propõe sanar uma dívida social decorrente da quase que variada ausência da diversidade cultural na historiografia brasileira (SANTOS, SILVA, 2019, p. 225).

De acordo com Ferraz, a aprovação da Lei 10.639/03 faz parte de um processo de luta na busca pelo reconhecimento e pela reparação das desigualdades entre populações brancas e negras presentes no Brasil, portanto deve ser vista como marco no que diz respeito ao avanço na democratização do currículo, bem como no reconhecimento e na valorização da história e da cultura da sociedade brasileira. Ou seja, no campo social, ela se institui como um ponto de partida para uma mudança, já no espaço educacional, significa ruptura profunda com um tipo de postura pedagógica que não reconhece as diferenças resultantes do nosso processo de formação nacional (FERRAZ, 2011, p. 20).

O desafio proposto na implementação no espaço educacional tem-nos mostrado que é quase impossível construir uma única abordagem que consiga abarcar todas as possibilidades de discussão acerca da História e da cultura afro-brasileira e africana, com isso, torna-se necessário estabelecer recortes sobre os temas e os espaços.

No entanto, mesmo cientes de tais detalhes, entendemos que é imprescindível construir discussões sobre a temática, seja em espaços formais e não formais, numa 
Revista do Corpo Discente do Programa de Pós-Graduação em História da UnB

Em TEMPO dE HistóRIAS | Brasília-DF | n. 36 | p. 29-46 | jan./jun. 2020.

ISSN 2316-1191

tentativa de inserção do conhecimento acerca das condições históricas e culturais vivenciadas por diferentes grupos na constituição da sociedade brasileira. Isso deve proceder de modo a garantir uma ressignificação e valorização cultural das matrizes africanas que formam a diversidade cultural brasileira, extinguindo, com isso, uma história de invisibilidade, silenciamento, exclusão.

Entre as inúmeras possibilidades de discussão acerca da história e da cultura afro-brasileira e africana, para este texto, propomos discutir a questão da religião afrobrasileira, levando em conta o contexto brasileiro. Sobre as religiões de matriz africana, Silva e Chada apontam que as diversas religiões presentes em diversas regiões do Brasil não apenas foram responsáveis pela reconstrução das crenças e dos cultos aos deuses africanos, como também assumiram importante papel no que diz respeito à manutenção de aspectos da cultura africana original, que acabaram espalhando-se pelo Brasil e até mesmo influenciando o surgimento de outras cultos, como a Umbanda no Rio de Janeiro e a Pajelança na Amazônia (SILVA; CHADA, 2016, p. 330-331).

Nesse sentido, para esse texto em específico, traremos como recorte a religião Umbanda, tendo como campo específico o viés religioso. Tal escolha se justifica, porque entendemos que a religião apresenta aspectos importantes e significativos da história e da cultura afro-brasileira para a construção da compreensão e do respeito à diversidade, bem como comporta em si um universo de signos, de símbolos, da construção de sentidos, podendo se tornar, com isso, um espaço profícuo de quebra de estereótipos e desconstrução de práticas preconceituosas. Cabe ressaltar que não temos a intenção de esgotar a temática, haja vista que a religião Umbanda é complexa, diversificada, pois dá ao estudioso uma gama de possibilidades de problematizações e análises.

Dessa forma, como material empírico, selecionamos um Ponto de Umbanda para análise, ou seja, cânticos ritualísticos consagrados e entoados pelos sacerdotes músicos da Umbanda, os Ogã ${ }^{1}$. Nossa escolha do Ponto como material de análise se fundamenta, primeiro, porque não há como deixar de considerar, como apontado por Silva Jr (2015), que a intolerância de natureza religiosa/racial configura uma das faces mais abjetas do racismo brasileiro, sendo necessária sua desconstrução. Segundo, como debatido por Moreira (2008), porque religião de matriz africana, no caso específico a Umbanda, tanto possui um caráter nitidamente mitológico e/ou épico, que sinaliza para um processo de rememoração histórica da presença de feitos de heróis, divindades e reis do passado ou dos fundamentos de sua religião, quanto traz para o presente as marcas do passado, da gênese histórica da Umbanda e do imaginário que permeia os praticantes desta religião, constituindo-se, com isso, um campo fértil para discussão acerca da história, da cultura e da religião afro-brasileira.

\footnotetext{
1 Ogã, palavra de origem Bantu que significa chefe, é o nome genérico para diversas funções masculinas nos rituais de Umbanda. O ogã não entra em transe, sendo que somente eles que são autorizados a tocar os atabaques nos ritos (PRATES, 2009).
} 
Revista do Corpo Discente do Programa de Pós-Graduação em História da UnB

Em TEMPO dE HistóRIAS | Brasília-DF | n. 36 | p. 29-46 | jan./jun. 2020.

ISSN 2316-1191

\title{
Umbanda: uma religião brasileira
}

De acordo com Sales (2017), historicamente entende-se que a Umbanda teve suas origens no Brasil entre o final do século XIX e o início do século XX, instituindo-se uma religião eminentemente brasileira e marcadamente forjada a partir da presença de ancestralidade e de herança de matrizes africanas e indígenas, do catolicismo popular e do kardecismo. Para Giumbelli (2002), essa definição temporal e espacial ainda constitui uma lacuna que movimenta diversas opiniões, sejam elas mobilizadas por seus adeptos ou por estudiosos, que se veem diante do desafio de defini-la. Esse fato ocorre diante da dificuldade de se apreender temporal e historicamente o "[...] começo de um fenômeno, o momento em que ele passa a existir enquanto tal e que, portanto, torna-se visível, representativo" (GIUMBELLI, 2002).

Já para Ortiz (1999), o surgimento da Umbanda deve ser compreendido dentro de um espaço histórico de mudanças, assinalando que é fruto de um movimento de transformação social que na História tem como marcos a Abolição da escravatura (1888), a Proclamação da República (1889) e o início do processo de inserção do homem negro e livre na sociedade, ou seja, ela se apresenta de forma mais intensificada em meio a uma série de transformações de ordem social, política e econômica, que teve como resultado um movimento de mudança cultural, isto é, "as crenças e práticas afrobrasileiras se modificam tomando um novo significado dentro do conjunto da sociedade global brasileira" (ORDIZ, 1999, p. 15). Ainda de acordo com o autor,

\begin{abstract}
$\mathrm{O}$ nascimento da religião umbandista deve ser apreendido neste movimento de transformação global da sociedade. A Umbanda não é uma religião do tipo messiânico, que tem uma origem bem determinada na figura do messias, pelo contrário, ela é fruto das mudanças sociais que se efetuam numa direção determinada. Ela exprime assim, através de seu universo religioso, esse movimento de consolidação de uma sociedade urbano industrial. A análise de sua origem deve, pois, se referir dialeticamente ao processo das transformações sociais que se efetuam (ORTIZ, 1999, p. 32).
\end{abstract}

Pinto (1971), ao propor uma definição para Umbanda, a partir de uma interpretação religiosa, sustenta que ela deve ser entendida como o "grande e verdadeiro culto que os espíritos humanos encarnados, na Terra, prestam a Obatalá , por intermédio dos Orixás ${ }^{3}$. Desse culto participam os espíritos elementais e os espíritos humanos desencarnados" (1971, p. 195). Seguindo a uma proposta etimológica de definição, Barbosa Júnior afirma que o termo "Umbanda" procede de duas línguas africanas: o umbundo e o quimbundo designa a arte de curandeiro, ciência médica, medicina (BARBOSA JUNIOR, 2014). De acordo com esse autor, com o passar dos anos sua prática passou a assinalar para um sistema religioso que assimila elementos religiosos afro brasileiros e o espiritismo kardecista, mesmo possuindo outros feitios, ainda que a Umbanda se consolide como "[...] um sistema religioso formado de diversas matrizes, com diversos elementos cada" (BARBOSA JUNIOR, 2014, p. 24).

\footnotetext{
2 Obatalá, esta palavra tem sido traduzida como o "Rei da Pureza". Obatalá tem o poder e o mando suficiente sobre todos os Orixás, é a cabeça da Religião Tradicional Yorubá, o o único juiz da religião, pois sua palavra é lei, se encarrega de julgar-nos aqui na Terra (MARINS, 2012).

${ }^{3}$ Divindades mitológicas (BARBOSA, 2012)
} 
Revista do Corpo Discente do Programa de Pós-Graduação em História da UnB

Em TEMPO dE HistóRIAS | Brasília-DF | n. 36 | p. 29-46 | jan./jun. 2020.

ISSN 2316-1191

Para além de uma definição categoricamente temporal e espacial, não que entendamos que tal não seja importante, mas que a questão histórica não é foco de nossa proposta de discussão, acreditamos que é quase impossível delinear em apenas algumas linhas o que constitui a Umbanda, fenômeno religioso brasileiro, uma vez que ela se apresenta de forma conceitual e prática a partir de um mosaico plural e diverso, acoplando em si uma significativa variação tanto de ordem teológica como litúrgica, porque ela pertence ao campo da tradição oral. Isso quer dizer que ela está sempre se reinventando e ressignificando seus ritos conforme as orientações das entidades sobrenaturais ${ }^{4}$.

Dessa forma, a Umbanda se apresenta a partir do estudo da existência e das questões referentes ao conhecimento da teogonia e da cosmogomia, isto é, se configura também no próprio rito. Ainda que não há como delineá-la em apenas um modelo religioso, uma vez que os diferentes espaços religiosos são idealizados e concebidos de forma particular a seus sacerdotes e seus filhos de santo. Não obstante, a Umbanda também se apresenta com uma variação em seu ritual, podendo ela ser enquadrada também como "[...] umbanda branca, umbanda tradicional, umbanda esotérica, umbanda traçada, umbanda de caboclo, umbanda de Jurema, umbandaime, umbanda sagrada etc. (CUMINO, 2010, p.83 a 87).

Neste âmbito, ainda é importante destacar que a Umbanda se forjou diante de uma mescla de ritos e preceitos, sincretizando santos católicos como estratégia tanto para se manter como para ser aceita na sociedade. Para Salle, esse fato fez com que a Umbanda se forjasse com contornos muito particulares e possuidores de um sistema religioso singular e inteiramente novo, pois [...] não se trata de uma religião uniforme, não há uma "linha" seguida por todos os seus praticantes, cada pai ou mãe de santo "faz" a sua Umbanda, de acordo com os preceitos que a sua entidade espiritual solicita (SALES, 2017, p, 29).

A Umbanda se caracteriza como uma religião porque apresenta, em sua organização, elementos necessários para tal, com um corpo de ideia do sagrado através das manifestações de orixás, guias (espíritos desencarnados) e demais entidades de Umbanda. Há, em seus espaços, a ocorrência de magias mediadas e propagadas pelo povo de santo, relatos de cura e da realização de trabalhos mágicos pelas entidades e sacerdotes; há a crença em uma vida futura, pois acredita na imortalidade do espírito e na reencarnação; a prática de cerimônias e rituais e a ocorrências de festas de cunho religiosos que atendem a um calendário próprio; por fim, há a explicação do universo através de uma teogonia e cosmologia própria.

A magia, neste espaço de discussão, pode ser refletida a partir de EvansPritchard (2005), que, ao discutir sobre magia, aponta que ela deve ser pensada dentro de sua própria lógica e suas regras de pensamento, sendo que ela, em seu processo de explicação das coisas, nunca exclui o conhecimento das causas naturais. Durkheim (1973) salienta que, onde há a divisão entre sagrado e profano, há a presença da religião. De acordo com o autor, o que muitos autores consideravam como mágico ele

4 Denominação que se dá a um espírito desencarnado. São divindades mitológicas do panteão Umbandista, que ultrapassa o natural, fora das leis naturais, fora do comum; extranatural (PRATES, 2009). 
Revista do Corpo Discente do Programa de Pós-Graduação em História da UnB

Em TEMPO dE HistóRIAS | Brasília-DF | n. 36 | p. 29-46 | jan./jun. 2020.

ISSN 2316-1191

pensa e considera como sendo religioso, uma vez que tais práticas estão nitidamente inseridas no social. Tais aspectos são fundamentais para criação e manutenção de uma religião. Sobre o conceito de religião, Geertz (2008) a define como um sistema de símbolo que representa a identidade de um povo. Para o autor:

[...] um sistema de símbolos que atua para estabelecer poderosas, penetrantes e duradouras disposições e motivações nos homens através da formulação de conceitos de uma ordem de existência geral e vestindo essas concepções com tal aura de fatualidade que as disposições e motivações parecem singularmente realistas (GERRTZ, 2008, p. 67).

Sendo assim, não tendo como intenção esgotar o tema proposto neste texto, compreendemos que a Umbanda é uma religião, sobretudo nascida no Brasil, que faz uso de práticas mágicas em suas cerimônias. Mesmo cientes da complexidade e variedade nas possibilidades de análise do todo que a religião Umbanda pode trazer, para a problematizarmos, nos pautaremos em apresentar e analisar um Ponto Cantado nos trabalhos umbandista, tendo como objetivo pensar seus aspectos culturais, religiosos, históricos e o imaginário de seus praticantes. Entende-se como Pontos Cantados músicas entoadas durante esses trabalhos - trabalho é o mesmo que cerimônia, ritual, tal como os próprios umbandistas definem.

Partimos da compreensão de que essa abordagem na Educação Formal, como é a proposta desse artigo, pode se tornar um veículo de inserção de diferentes grupos como protagonistas nos processos históricos e "atores sociais", os quais são vitais para o entendimento das manifestações culturais presentes no Brasil, pois, além de assinalarem para a diversidade brasileira, podem auxiliar na diminuição dos preconceitos, promovendo uma educação étnico-racial, permitindo a afirmação das identidades e a valorização histórica como sujeitos atuantes na História.

\section{Pontos cantados como fonte para análise no Ensino de História}

$\mathrm{Na}$ Umbanda, terreiro, tendas, templos, centros-espíritas, entre outras terminologias, correspondem ao local em que incidem as celebrações ritualísticas e de encontro dos umbandistas dessa religião. A música neste espaço é algo muito presente, sendo ela cantada em companhia de instrumentos, como, por exemplo, os tambores. De acordo com Rosafa (2008), as músicas são nomeadas como Pontos e/ou cânticos e, dentro da Umbanda, cumprem o papel tanto de condutor como também de 'combustível' dessa manifestação religiosa.

A musicalidade está presente em quase toda movimentação que circunda o ambiente ritualístico, e sua função não se detém a apenas alegrar ou distrair os umbandistas no momento dos trabalhos ritualísticos, mas, sim, são Pontos Cantados com múltiplas finalidades, entre elas, invocar entidades, abrir e fechar as celebrações, servir como componente para pedir forças espirituais, para afastar espíritos sem luz e/ou sem esclarecimento, entre outros desígnios (PRATES, 2009). Isto é, apresenta-se em quase todos os momentos dos trabalhos, sendo também um elo entre o mundo terreno e o sagrado. De acordo com Amaral, a música nas religiões afro-brasileiras,

[...] desempenha um papel fundamental. É um dos principais veículos por meio dos quais os adeptos organizam suas diversas experiências religiosas e invocam 
Revista do Corpo Discente do Programa de Pós-Graduação em História da UnB Em TEMPO dE HistóRIAS | Brasília-DF | n. 36 | p. 29-46 | jan./jun. 2020.

os orixás, caboclos e outras entidades espirituais que os incorporam em festas, giras, sessões e outras cerimônias coletivas. Nesses rituais, a música é produzida por diversos instrumentos (atabaques, cabaças, chocalhos, agogôs, ganzás, etc), que variam segundo os ritos, acompanhados por cantos que são considerados formas de orações que unem o homem ao sagrado (AMARAL, 2006, p. 190-191)

É possível perceber, com isso, que os Pontos Cantados tomam outra dimensão nesses espaços religiosos, pois ultrapassam uma concepção de adorno. Eles se tornam também a base do momento ritualístico, fazendo parte de um todo sagrado. Ao serem evocados em diversos momentos, cumprem diferentes demandas, entre elas, são utilizados, "[...] para iniciar a sessão, para a purificação do terreiro com o uso de defumadores, para a saudação dos Orixás, para professar a fé" (ALMEIDA; SOUZA, 2012 , p. 01), ainda assume outras funções no momento do ritual, "[...] impregnam o ambiente de determinadas energias enquanto o libera de outras, representam imagens e traduzem sentimentos ligados a cada vibração" (BARBOSA JUNIOR, 2014, p.40).

Em sua maioria, os Ponto Cantados são escritos em formato de poemas e apresentam uma narrativa estritamente mitológica que rememoram no imaginário dos umbandistas os feitos de heróis, divindades, reis e sujeitos comuns, bem como trazem para o presente uma narrativa com traços, experiências e marcas do passado e de seus ancestrais, ou seja, a música neste espaço assume o papel de rememoração da própria história da religião e dos negros, dessa forma, também da história, da cultura e da religiosidade brasileira.

É pertinente ainda pontuar, como destacado por Almeida e Souza (2016), que, diferente de outras religiões, as religiões afro-brasileiras não possuem livros ou textos sagrados, como, por exemplo, a religião cristã e a budista, mas se valem tão somente da narrativa e tradição oral para propagarem e manterem seus mitos, crenças e tradição vivos. A narrativa oral ocupa lugar central nessa religião, haja vista que seus cânticos e rituais são, nesse sentido, instrumentos de reafirmação e de propagação de sua história e religiosidade. Para Cumino (2016), “[...] o território perdido na diáspora africana é celebrado por meio da oralidade dos cânticos e do mundo simbólico dos terreiros. Na gira, os povos de santo resgatam, através dos cânticos, seu universo referencial" (2016, p. 104). Os Pontos Cantados tanto atualizam, como também evoca uma ancestralidade, podendo ser tomados nesse sentido como documentos da história e da memória acerca da religião, ou seja, são rastros de história e de memória que trazem para o presente a religiosidade e a história dos africanos e afro-brasileiros.

Nesse sentido, entendemos que os Pontos Cantados são fecundos no que diz respeito a elementos tanto da história quanto das religiões afro-brasileiras, podendo com isso serem problematizados e tomados como fonte de pesquisa no Ensino de história no espaço da educação formal, uma vez que podem ser utilizados como documentos que comportam traços e vestígios do passado. Com isso, colaboram na construção da compreensão e do respeito à diversidade, já que tais religiões não estão relacionadas apenas aos negros, e sim a toda a sociedade brasileira.

A apropriação e o uso dos Pontos Cantados como fonte para a pesquisa histórica atendem a uma série de mudanças no campo historiográfico e na ampliação dos documentos como fontes de pesquisa, visto que propõe romper com o método 
Revista do Corpo Discente do Programa de Pós-Graduação em História da UnB

Em TEMPO dE HistóRIAS | Brasília-DF | n. 36 | p. 29-46 | jan./jun. 2020.

ISSN 2316-1191

tradicional positivista do fazer historiográfico, em especial a partir da década de 1980, momento em que novos objetos, perguntas e perspectivas históricas foram postas como processo de construção e problematização da História. No que diz respeito à fonte, Lombardi assinala que,

As fontes resultam da ação histórica do homem e, mesmo que não tenham sido produzidas com a intencionalidade de registrar a sua vida e o seu mundo, acabam testemunhando o mundo dos homens em suas relações com outros homens e com o mundo circundante, a natureza, de forma que produza e reproduza as condições de existência e de vida (LOMBARDI, 2004, p. 155).

Na disciplina de História, como exemplo, esse material pode - a partir de um viés criterioso de análise documental - ser tomado, problematizado e analisado pelo professor como documento histórico, haja vista que ele comporta elementos da história, da religião e da cultura afro-brasileira. Definimos como fontes, tal como orientam os Parâmetros Curriculares Nacionais (PCNs), “[...] as mais diversas obras humanas produzidas nos mais diferentes contextos sociais e com objetivos variados" (BRASIL, 1998, p. 83). Diante disso, entendemos que os Pontos Cantados, como produção humana, ajustam-se a essa definição, podendo ser tomados como materiais e documentos possíveis para problematização da história, da sociedade e da religiosidade brasileira, contribuindo, com isso, para a produção de conhecimento histórico no âmbito do Ensino de História. Os Parâmetros Curriculares Nacionais (PCNs) propõem o uso e reconhece a importância do trabalho com fontes históricas na sala de aula. Para o PCN's, seu uso em sala de aula,

Com efeito, exploram-se as fontes com a intenção de levar o aluno a percebê-las como uma produção histórica, que se deve localizar no tempo e no espaço, sendo lidas como uma versão dos acontecimentos produzidos por determinados sujeitos históricos. Desta forma, enfatiza-se o aspecto seletivo, parcial e provisório do conhecimento histórico. Compreende-se, então, a atenção dada à leitura das fontes, levando o aluno ao reconhecimento de suas condições de produção (BRASIL, 2007, p. 23).

Ao utilizar em sala de aula o Ponto Cantado como documento histórico, partirmos do entendimento de que as fontes históricas são todos os vestígios produzidos pelos seres humanos ao longo do tempo, como defendido por Marc Bloch (2010), e de que não são neutros na sua produção. Assim sendo, instituem-se como possibilidade de fonte de análise para o Ensino de História no espaço da sala de aula, como proposta de problematização sobre o passado, em que o documento assume o papel na prática do ensino, contribuindo, assim, para que fomente compreensão e aprendizagem da História.

Sendo assim, a título de documento para a análise, selecionamos como fonte o Ponto Cantado de Pretos Velhos, intitulado "Esperança Para Um Novo Amanhecer". Apresentamos, a partir da fonte, a possibilidade de problematização e possíveis análises, tendo como enfoque os elementos e traços históricos da experiência dos negros no Brasil. Vale destacar que a Umbanda é constituída de várias categorias, conhecidas pelos umbandistas por linhas. Entre elas, existe a linha de Preto Velho. Na linha de Preto Velho, conforme a cosmovisão da Umbanda, são os espíritos de velhos negros (antepassados e ancestrais negros) de origem mitológica do Brasil Colonial, período da escravização, que os umbandistas/ médiuns incorporam. São personagens 
Revista do Corpo Discente do Programa de Pós-Graduação em História da UnB

Em TEMPO dE HistóRIAS | Brasília-DF | n. 36 | p. 29-46 | jan./jun. 2020.

ISSN 2316-1191

míticos que representam sabedoria e humildade para os umbandistas. Segundo Prates (2009), “(...) o panteão sagrado é denominado por linhas: Linha da Umbanda, Linha da Quimbanda. Dentro dessa linha, há a presença de entidades sobrenaturais classificadas por sub-linhas, como linha de Preto Velho ou linha das Almas, linha de Caboclo, linha de Escora e linha de Pomba-Gira” (PRATES, 2009, p. 132).

É importante ressaltar mais uma vez que os Pontos Cantados são música, mesmo se tratando especificamente de uma música de cunho religioso, tal como já debatido. Por ser música, há todo um critério metodológico de análise sobre essa fonte, entre esses critérios, destacamos: a necessidade do conhecimento e da sensibilidade específicos para melodias e letras; o contexto histórico de sua produção e as especificidades de cada gênero.

No caso específico do uso dessa fonte no espaço da Educação Formal, Hermeto e Soares salientam que "ao professor de história cabe uma tarefa ainda mais complexa: utilizar a música como objeto de estudo e como fonte para a construção de capacidades voltadas à aprendizagem e à construção do conhecimento histórico pelos estudantes" (HERMETO; SOARES, 2017, p. 04). Isto é, a proposta de análise perpassa incialmente a análise da letra; o gênero musical e a construção de mentalidade de determinada época história (ABUD; SILVA; ALVES; 2010). Sobre esse ponto de discussão, Napolitano afirma que, ao tratarmos a música como fonte, é preciso:

\begin{abstract}
Considerar as fontes áudio visuais e musicais como um outro tipo qualquer de documento histórico, portadora de uma tensão entre evidência e representação [...]. Perceber as fontes áudio visuais e musicais em suas estruturas internas de linguagem e seus mecanismos de representação da realidade, analisando, a partir daí, sua condição de 'testemunho' de uma dada experiência histórica e social [...]. Articular a linguagem técnico - estética das fontes áudio visuais e musicais e as representações da realidade histórica ou social nela contida (NAPOLITANO, 2006, p. 281).
\end{abstract}

Para Bittencour (2008), há um duplo desafio no uso da música como fonte: conseguir distinguir a diferença entre ouvir uma música e pensar sobre a música, ainda que, a música como documento deve ser analisada mediante a interação com o ritmo, o acompanhamento, a velocidade, a tonalidade, a melodia e a estrutura da letra (2008, p. 388). Diante disso, ao propor o uso o Ponto Cantado como fonte para o Ensino de História, não temos aspiração de esgotar a fonte ante as possibilidades de análise que o documento possui. Cientes disso, neste texto, iremos priorizar tão somente a letra da música, respeitando os seus limites e as lacunas no que diz respeito a informações de registro.

Dessa forma, ao propor a utilização do Ponto Cantado de Umbanda no contexto da sala de aula, não intencionamos fazer dos alunos um historiador profissional, mas propor uma aproximação com o trabalho do historiador como caminho possível para aguçar neles curiosidade, criatividade e capacidade de reflexão e análise, ou seja, entendemos a fonte como recurso na produção de conhecimento histórico. Assim sendo, a fonte deve ser vista em sala de aula como meio de desenvolver nos alunos critérios, como: observação, problematização, análise, formulação de hipóteses, crítica e construção do conhecimento. 
Revista do Corpo Discente do Programa de Pós-Graduação em História da UnB

Em TEMPO dE HistóRIAS | Brasília-DF | n. 36 | p. 29-46 | jan./jun. 2020.

ISSN 2316-1191

\section{Possibilidade de abordagem da fonte no Ensino de História}

Talvez um dos maiores desafios que o professor da Educação Básica, do Ensino de História, enfrente no espaço da sala de aula seja como manusear os documentos de forma que eles se tornem fontes para a construção do conhecimento histórico. E tal fato talvez seja, porque em diversos espaços escolares ainda prevalece o modelo educacional tradicional, no qual tende a privar os alunos de se tonarem protagonista no processo de ensino e aprendizagem. Numa proposta de romper com esse modelo, professor e alunos se veem desafiados a construir e adquirir uma bagagem conceitual e metodológica que lhes permita compreender os instrumentos e procedimentos básicos da produção do conhecimento histórico, isso a partir de um profundo respeito aos limites da sala de aula e dos alunos em níveis de complexidade.

De acordo com Bittencourt (2008), a utilização de documentos na perspectiva do Ensino de História deve perpassar pelo menos dois pontos importantes. Primeiro, é essencial que o professor planeje e conheça os recursos que serão utilizados, ou seja, que de antemão tenha domínio sobre a fonte documental e que sabia antecipadamente fazer a crítica interna e externa ao documento selecionado. Segundo, os alunos devem ser previamente preparados sobre o que é fonte histórica e qual o seu uso na construção do conhecimento, além de serem orientados sobre as possibilidades de uma relação ao contexto histórico em estudo.

A autora ainda pondera sobre quais os caminhos plausíveis para uma análise documental satisfatória em conjunto com os alunos em sala de aula. Para Bittencourt, é necessário descrever o documento para os alunos, destacando as principais informações nele contidas; mobilizar, ainda que sumariamente, os saberes e conhecimentos prévios que os alunos possuem sobre o documento e o assunto nele contido; posteriormente, explicar o documento, associando informações e saberes sistematizados sobre o assunto; depois situar o documento em relação ao seu autor; identificar a origem/natureza do documento e explorá-lo; por fim, exercitar a crítica ao documento, apresentando aos alunos limites e contribuições para a construção do conhecimento em relação ao contexto histórico no qual estão trabalhando. Essa proposta de análise aproxima-se do que Le Goff (1994), compreende como uma crítica acerca da fonte documental, sugerindo que o objeto documental possui uma estrutura interna e externa ao texto. É possível perceber que Bittencourt (2008) traça todo um caminho de estudo em sala de aula com a participação dos alunos, para que esses também façam parte da construção do conhecimento.

Sobre a análise de documentos, Cândido (2006) assinala que a estrutura interna é composta por aquilo que está efetivamente dentro do texto, como as palavras, a rima, a métrica e outros recursos, quando utilizadas as fontes escritas, como é a proposta deste artigo. Já a estrutura externa é aquilo que se encontra fora do texto, em que se encaixam os aspectos históricos, sociais e filológicos referentes ao texto.

Após essa explanação, o último passo é a sistematização do conhecimento, sendo que o objetivo a ser alcançado é levar os alunos é perceber as fontes como uma produção histórica, temporal e espacial (BRASIL, 2007, p. 23). A proposta não se dá em transformar os alunos e pequenos historiadores, mas aproximá-los do processo de 
Revista do Corpo Discente do Programa de Pós-Graduação em História da UnB

Em TEMPO dE HistóRIAS | Brasília-DF | n. 36 | p. 29-46 | jan./jun. 2020.

ISSN 2316-1191

construção histórica, de forma que compreendam que eles também são sujeitos protagonista da História.

Abaixo apresentaremos uma proposta de análise documental de um Ponto Cantado e com um roteiro específico inspirado nas discussões que Bittencourt propõe em seus estudos acerca do uso de fonte histórica no Ensino de História.

Proposta de roteiro para análise de fonte documental:

\begin{tabular}{|c|c|}
\hline $\begin{array}{c}\text { Ponto de Preto Velho: } \\
\text { Esperança Para Um Novo } \\
\text { Amanhecer }\end{array}$ & Roteiro de análise \\
\hline $\begin{array}{l}\text { Negro canta, negro dança } \\
\text { Liberdade fez valer } \\
\text { Não existe sofrimento, não existe } \\
\text { mais chibata } \\
\text { Só existe a esperança para um novo } \\
\text { amanhecer (BIS) } \\
\text { Povo negro, povo forte } \\
\text { Trabalhavam pro senhor } \\
\text { E sofriam as maldades praticadas } \\
\text { pelo feitor } \\
\text { O sangue, o suor e a lágrima } \\
\text { Renovavam a força pra lida } \\
\text { Pois sabiam que o sofrimento } \\
\text { purificava pra nova vida }\end{array}$ & 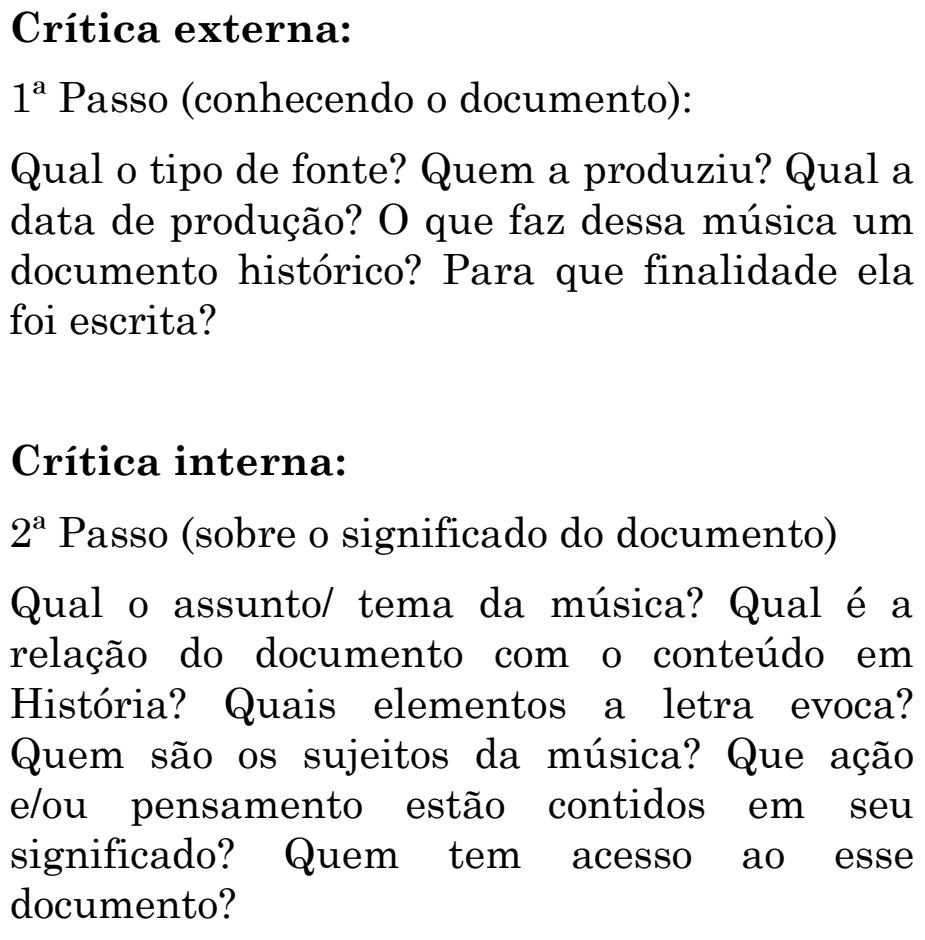 \\
\hline $\begin{array}{l}\text { Ecoou um canto forte na senzala } \\
\text { Ecoou um canto forte na senzala }\end{array}$ & \\
\hline $\begin{array}{l}\text { Negro canta, negro dança } \\
\text { Liberdade fez valer } \\
\text { Não existe sofrimento, não existe } \\
\text { mais chibata } \\
\text { Só existe a esperança para um novo } \\
\text { amanhecer }\end{array}$ & \\
\hline
\end{tabular}


Do Congo ou de Angola ou de Mina Bahia, Aruanda ou Cambinda São os velhinhos da Umbanda Que encaminham nossas vidas Esqueceram o terror da senzala Do cativeiro, as crueldades E voltaram pra essa terra Pra prestar a caridade

Ecoou um canto forte na senzala Ecoou um canto forte na senzala

Negro canta, negro dança Liberdade fez valer Não existe sofrimento, não existe mais chibata

Só existe a esperança para um novo amanhecer

Intérprete: Edvander de Oliveira

Fonte: Letra e vídeo disponível no site: https://www.letras.mus.br/juliana-d-passos-e-amacumbaria/ponto-de-preto-velho-esperanca-para-um-novo-amanhecer/.

O objetivo dessa proposta de roteiro para análise de fonte documental é apresentar aos estudantes que os documentos não devem ser vistos no espaço da sala de aula, em especial na disciplina de História, como meramente um material ilustrativo. Pelo contrário, cabe perceber em conjunto com os estudantes que os documentos podem ser tomados como importante fonte de informação que traz à luz aspectos históricos e sociais de determinado tempo e espaço - isso a partir das perguntas que aluno e professor poderão fazer a ele. O espaço da sala de aula pode se tornar um profícuo ambiente para construção de situações problemas, isto é, construir em conjunto com os estudantes questões/problemas. Com isso em grupo, o espaço da sala de aula pode tornar-se um momento para troca ideias, processo de investigação e desenvolvimento de noções e habilidades interpretativas.

O roteiro nesse sentido surge como um instrumento metodológico de análise documental, que, posto em sala, auxilia do processo de reflexão sobre o procedimento acerca da construção do conhecimento histórico, a partir de uma metodologia de análise da crítica interna e externa ao documento. De acordo com Adalberto Marson (1984), o uso de documentos em sala de aula apresenta dois pontos importantes: primeiro, que é necessário que o professor conheça como o documento é utilizado na 
Revista do Corpo Discente do Programa de Pós-Graduação em História da UnB

Em TEMPO dE HistóRIAS | Brasília-DF | n. 36 | p. 29-46 | jan./jun. 2020.

ISSN 2316-1191

investigação histórica; segundo, que ele saiba fazer essa transposição para o espaço da sala de aula.

Sendo assim, a proposta de roteiro se dá porque acreditamos que o uso de documento para análise contribui para o desenvolvimento crítico e analítico dos estudantes no que diz respeito ao pensamento histórico. Mesmo cientes de que os documentos, ao serem produzidos, não almejam uma função didática, ainda assim podem ser utilizados pelo professor, a partir de uma metodologia apropriada, como prática pedagógica.

\section{Possibilidade de análise em sala de aula:}

- Primeira: A narrativa presente no Ponto de Preto Velho "Esperança para um novo amanhecer" traz em sua letra aspectos da história do Brasil, em especial quando faz alusão ao período escravocrata, a saber: "Ecoou um canto forte na senzala" e "Trabalham pro senhor/ e sofriam as maldades praticadas pelo feito". A letra da música ao abordar elemento do passado (escravo, feitor, senzala) dialoga com o que os estudiosos das religiões afro-brasileiras apontam na musicalidade como o espaço de rememoração da história do povo negro, através da oralidade, tal como salientado por Cumino (2016), “[...] o território perdido na diáspora africana é celebrado por meio da oralidade dos cânticos e do mundo simbólico dos terreiros. $\mathrm{Na}$ gira, os povos de santo resgatam, através dos cânticos, seu universo referencial". De acordo com Almeida e Souza (2016), é comum encontrar, nos Pontos Cantados, elementos da história africana e afro-brasileira, haja vista que as religiões afro-brasileiras historicamente recorram a tradição oral como forma de manutenção de sua história e religião. Tais pontos podem ser problematizados no espaço da sala de aula, sobretudo quando o professor considera a importância da oralidade como fonte fecunda para a produção do conhecimento histórico.

- Segunda: a letra pode ser analisada a partir da presença de ancestralidade e de herança das três religiões que, segundo os estudiosos, compõe a Umbanda: as religiões afro-brasileiras, catolicismo popular e kardecismo.

Matriz africana e Kardecista: Nos refrãos "São os velhinhos da Umbanda/ Que encaminham nossas vidas / E voltaram pra essa terra Pra prestar a caridade”, há a presença da ancestralidade e da pluralidade das existências, em que os humanos, mesmo após a morte, continuam mantendo contato com os viventes - isso para os espíritos mais evoluídos. Sobre a experiência da morte, no caso do espiritismo, há o processo de reencarnação, que se caracteriza pela constante evolução espiritual do ser humano. Já na Umbanda, os espíritos considerados evoluídos podem manter contato com os seres viventes, dando-lhe conselhos. Mesmo ambas as religiões não sendo iguais, apresentam suas semelhanças, entre elas: são espiritualistas; acreditam em Deus (cristão); ocorrem fenômenos mediúnicos e aceitam reencarnação. No espaço da sala de aula, a abordagem neste trecho da letra pode se tornar um espaço de debate $\mathrm{e}$ problematização acerca da construção da religiosidade brasileira, que não se finda tão 
Revista do Corpo Discente do Programa de Pós-Graduação em História da UnB

Em TEMPO dE HistóRIAS | Brasília-DF | n. 36 | p. 29-46 | jan./jun. 2020.

ISSN 2316-1191

somente na presença Católica, mas comporta em si elementos de outros povos, com suas características, histórias e experiências humanas e sagradas. Tal debate pode se tornar um espaço de discussão e combate à discriminação, precipuamente contra o preconceito em torno das religiões de matriz africana, tão presente ainda na sociedade brasileira.

Matriz cristã (catolicismo popular): "O sangue, o suor e a lágrima/ Renovavam a força pra lida / Pois sabiam que o sofrimento/ purificava pra nova vida”. Neste trecho da letra, há uma supervalorização no sofrimento como percurso para a purificação da vida e da alma. No catolicismo, o sofrimento, o sacrifício e a mortificação da carne são vistos como elementos para a elevação do homem, característica presente tanto na história de vida e morte dos santos e santas canonizadas, como também na história de Cristo, visto como maior mártir do cristianismo (SILVA, 2014). Neste ponto de problematização, é possível debater em sala de aula com os alunos a respeito de como a religiosidade brasileira é mesclada por uma série de símbolos e concepção do sagrado, sendo que os aspectos inerentes à religião atravessam a própria história do Brasil. É possível ainda problematizar como, por séculos, a religião Católica foi a única aceita no período colonial e imperial, havendo a mudança tão somente com a Proclamação da Republica em 1889, quando houve a separação entre o Estado e a Religião, bem como a instituição do Estado laico.

\section{- Terceiro (perspectiva política):}

Como já apresentado, a Umbanda tem como marco de sua organização religiosa o século XIX e XX. Mesmo não sendo precisa sua demarcação histórica, os indícios de sua formação, como problematizado pelos autores abordados, temporalmente datam nesse período. Por mais que a letra da música aborde em seus versos elementos do Brasil escravocrata, ela ainda elabora uma narrativa de rememoração do passado, trazendo para o presente a experiência da escravidão. No Ensino de História, essa abordagem pode ocorrer como demarcação temporal, o que historicamente conhecemos como o Período Republicano. Tal fato se dá por elementos que o próprio Ponto Cantado oferece para análise, são eles: "Negro canta, negro dança / Liberdade fez valer / Não existe sofrimento, / não existe mais chibata / Só existe a esperança para um novo amanhecer”. Tais versos podem ser vistos como a anunciação de um "novo tempo" experimentado pela sociedade a partir da Proclamação da República (1889), princípio de liberdade civil, política e religiosa. Por mais que não tenha como datar precisamente a criação da música, ela, ainda assim, assinala não para um país colonizado e escravocrata, mas para um país que experimentava os anos iniciais da liberdade, sendo ela promulgada diante de Lei, a Constituição de 1891, que garantia ao cidadão, na Seção II, da Declaração de Direitos, Art 72 - "A Constituição assegura a brasileiros e a estrangeiros residentes no País a inviolabilidade dos direitos concernentes à liberdade, à segurança individual e à propriedade”. Esse Artigo foi revogado pela 
Revista do Corpo Discente do Programa de Pós-Graduação em História da UnB

Em TEMPO dE HistóRIAS | Brasília-DF | n. 36 | p. 29-46 | jan./jun. 2020.

ISSN 2316-1191

Redação dada pela Emenda Constitucional de 3 de setembro de 1926, mas ainda se garantia a liberdade do cidadão brasileiros e a estrangeiros residentes no país.

No espaço da sala de aula, a partir da fonte utilizada, é possível problematizar em diálogo com referencial teórico que a Proclamação da República incorporou o lema liberdade, igualdade e fraternidade (GUIMARÃES, 2011) e propôs novas aspirações de Estado, de direitos, de nação, de solidariedade social e de cidadania, Entre as propostas de mudanças, estavam a separação entre a Igreja e o Estado, abrindo espaço, com isso, para a manifestação de outros credos e religião que não se restringia tão somente à religião Católica, haja vista o discurso de liberdade que a Constituição de 1891 trazia em seu corpo. Diante disso, a música, ao abordar em sua letra a "a esperança para um novo amanhecer" e "Liberdade fez valer", pode estar se referenciando ao contexto em que a Umbanda se estabelece no Brasil como religião.

\section{Considerações finais}

Como debatido no início deste texto, a proposta da inserção da temática da História e Cultura Africana e afro-brasileira nos currículos escolares no Brasil, legitimada a partir da promulgação da Lei 10.639/2003, se insere tanto a partir de lutas e reivindicações no que diz respeito à valorização e ao reconhecimento da presença negra na formação do Brasil, como também é vista como uma possibilidade de rompimento com os anos de preconceito e racismos presentes ainda na sociedade, sendo a sala de aula o espaço propício para que debates que proponham uma educação antirracista ocorram.

Nesse sentido, para a inserção da temática no Ensino de História, tomamos o Ponto Cantado de Umbanda como possível fonte para a pesquisa histórica em sala de aula, ou seja, propusemos uma discussão na qual utilizamos a letra de uma música para pensar a história, a religião e os aspectos políticos oportunizados por ela para o debate. Mesmo não tendo a intenção de esgotar o documento e o tema, nosso objetivo se deu em apresentar possibilidades de avanços e ampliação de fontes documentais no Ensino de História da Educação formal, com o intuito de romper com um ensino tradicional de reprodução de conteúdo e inserir os alunos no processo de construção do conhecimento histórico. Ao propor a análise de um Ponto Cantado de Umbanda, tencionamos também propor uma discussão que insira a história e a religiosidade de matriz afro-brasileira no espaço escolar, numa tentativa de romper com o preconceito existente sobre tais. Nesse sentido, apresentamos a possibilidade de debate a partir de um viés não somente religioso como também histórico e político.

Acreditamos que ainda há muito a ser problematizado, discutido e ampliado no debate da temática, no entanto intuímos que, quando fazemos uso de fontes documentais para a observação, problematização e análise dos conteúdos em História no espaço da educação formal, o processo de construção do conhecimento histórico ocorra de forma mais significativa, bem como que essa educação se torne o caminho 
Revista do Corpo Discente do Programa de Pós-Graduação em História da UnB

EM TEMPO DE HISTÓRIAS | Brasília-DF | n. 36 | p. 29-46 | jan./jun. 2020.

ISSN 2316-1191

possível para a construção de uma sociedade antirracista, que saiba perceber e conhecer sua História a partir da múltiplas relações humanas nela existentes.

\section{Referências:}

ABUD, Kátia Maria; SILVA, André Chaves de Melo; ALVES, Ronaldo Cardoso. Ensino de História. São Paulo: Cengage Learning, 2010.

AMARAL, Rita e SILVA Vagner Gonçalves da. Foi conta para todo canto: as religiões afro-brasileiras nas letras do repertório popular brasileiro. In. Revista Afro-Asia, Salvador, UFBA, n.34, pp. 189-235, 2006.

BARBOSA JÚNIOR, Ademir. O livro essencial de Umbanda. São Paulo: Universo dos Livros, 2014.

BARBOSA, Daniela dos Santos. O conceito de orixá no candomblé: a busca do equilíbrio entre os dois universos segundo a tradição iorubana. In: Sacrilegens. Juiz de Fora, v. 9, n.1, p. 76-86, jan-jun/2012.

BITTENCOURT, Circe Maria Fernandes. Identidade nacional e ensino de História do Brasil. In KARNAL, L. História na sala de aula: conceitos, práticas e propostas. São Paulo: Contexto, 2003.

. Ensino de História: fundamentos e métodos. São Paulo: Cortez, 2008.

BLOCH, Marc. Apologia da História ou ofício do historiador. Tradução André Telles. Rio de Janeiro: Jorge Zahar Ed., 2001.

BRASIL. Ministério da Educação. Guia de livros didáticos PNLD 2008: História. Brasília: MEC, 2007. (Anos Finais do Ensino Fundamental).

CÂNDIDO, Antônio. Literatura e Sociedade. 9a edição. Ouro sobre Azul/I Rio de Janeiro 2006.

CANDAU, Vera M. (org.). Sociedade, educação e cultura (s): questões e propostas. Petrópolis: Vozes, 2002.

COUTINHO, A. C. C.P. Raça, Etnia e a Escola: Possibilidades de Implementação da Lei 10.639/031. In. Cadernos da Pedagogia. Ano 02, Volume 02, Número 04, agosto/dezembro, 2008.

CUMINO, A. História da Umbanda: uma religião brasileira. São Paulo: Madras, 2010. Disponível

em: http://repositorio.ufes.br/bitstream/10/6982/1/Livro\%20digital Giramundos.pdf. Acesso em 29 de abril de 2020.

DURKHEIM, Émile. As formas elementares da vida religiosa. São Paulo: Paulinas, 1973.

EVANS-PRITCHARD, Edward E. Bruxaria, oráculos e magia entre os Azande. Rio de Janeiro: Zahar, 2005.

Ferraz, L. A.. (2011). Lei $n^{\circ}$ 10.639/03: uma nova possibilidade de reconhecimento da história e cultura afro-brasileira e africana (Trabalho de conclusão de curso). 
Revista do Corpo Discente do Programa de Pós-Graduação em História da UnB

Em TEMPO dE HistóRIAS | Brasília-DF | n. 36 | p. 29-46 | jan./jun. 2020.

ISSN 2316-1191

Universidade Estadual de Londrina - UEL, Londrina, PR, Brasil. Recuperado de http://www.uel.br/ceca/pedagogia/pages/arquivos/LUCIANE\%20APARECIDA\%20FER $\underline{\text { RAZ.pdf }}$

FREITAS, B. T. de \& PINTO, T. S. Doutrina e Ritual de Umbanda. Rio de Janeiro: Espiritualista, 1970.

FONSECA, Maria Nazareth Soares (org.). Brasil afro-brasileiro. $2^{\mathrm{a}}$ ed. Belo Horizonte: Autêntica, 2001.

Fonseca, Selva G. Didática e prática de ensino em História. São Paulo: Pairus, 2007.

GIUMBELLI, E. Zélio de Moraes e as origens da umbanda no Rio de Janeiro. In. SILVA, V. G. (org.) Caminhos da alma: memória afro-brasileira, São Paulo, Summus, 2002.

GEERTZ, Clifford. A Religião como Sistema Cultural. In: A Interpretação das Culturas. Rio de Janeiro: Ed. LTC, 2008.

LE GOFF, Jacques. História e Memória. Tradução de Bernardo Leitão. Campinas-SP: Editora da UNICAMP, 1994.

HERMETO, Miriam; SOARES Olavo Pereira. Música e ensino de história. In. Revista História Hoje. Vol. 6, nº 11, 2017.

LOMBARDI, J. C. e NASCIMENTO, M. I. M. (Org). Fontes, História e Historiografia da Educação. Campinas: Autores Associados, 2004. p. 141-176.

MALANDRINO, Brígida Carlo. "Há sempre confiança de se estar ligado a alguém": dimensões utópicas das expressões da religiosidade bandu no Brasil. Tese de doutorado em Ciências da Religião. PUC-SP, 2010.

MARSON, Adalberto. Reflexões sobre o procedimento histórico. In: SILVA, Marcos (Org.). Repensando a história. Rio de Janeiro: Marco Zero: Anpuh, 1984.

MOREIRA, Carina. Metáforas da Memória e da Resistência: uma análise dos pontos cantados na Umbanda. In Anais do XI Congresso Internacional da ABRALIC. USP. 2007.

MARINS, Luiz L. Òrìsà dídá ayé: òbátálá e a criação do mundo ioruba. In: África, São Paulo. v. 31-32, p. 105-134, 2011/2012.

PINTO, Altair (org.). Dicionário da Umbanda. Rio de Janeiro: Eco, s/d.

PRANDI, R. Herdeiras do Axé: Sociologia das religiões afro-brasileiras. São Paulo: Hucitec, 1996.

PRATES, A. E. "Exu agodô, o sangue eu lhe dei, mas a carne eu não dou”. Traços característicos da identidade de Exu-Sertanejo, expressos no imaginário religioso AfroSertanejo da cidade de Montes Claros/ MG, contidos na tradição oral. (dissertação) PUC-SP São Paulo, 2009.

Supremo Tribunal Federal e o Ensino Religioso. In. Revista Brasileira de Estudos Jurídicos. Vl. 12, n. 2, jul./dez. 2017. 
Revista do Corpo Discente do Programa de Pós-Graduação em História da UnB

Em TEMPO dE HistóRIAS | Brasília-DF | n. 36 | p. 29-46 | jan./jun. 2020.

ISSN 2316-1191

SANTOS, Bergstos Luan; SILVA, Jaciely Soares da. Ensino da História da cultura afro-brasileira e o conflito democrático: algumas aproximações. In. Educação: ressonâncias teóricas e práticas. Volume 1. São Carlos: Pedro \& João Editores, 2019.

SILVA JR, Hédio. Notas sobre o sistema jurídico e intolerância religiosa no Brasil. In: SILVA, Vagner Gonçalves da (org.). Intolerância Religiosa: impactos do neopentecostalismo no campo religioso afro-brasileiro. 1. ed. 1. reimpr. São Paulo: Editora da Universidade de São Paulo, 2015.

SILVA, Edson Santos; CHADA, Sonia. Pontos rituais: a religiosidade afro-brasileira nas composições de Waldemar Henrique. In. II Encontro Regional da Associação Brasileira de Etnomusicologia II Colóquio Amazônico de Etnomusicologia. Disponível em: https://www.academia.edu/31974862/ANAIS__II_ABETNORTE_e_II_COL.ETNO.pdf. Acesso em: 20 de maio de 2020.

SCHWARCZ, L. M. Racismo no Brasil. São Paulo: Publifolha, 2001. 